\title{
LUJO, PODER Y MAGNIFICENCIA EN LA CASA Y CORTE DE JUAN DE LA CERDA Y VIQUE, II DUQUE DE MEDINACELI (1485-1544)*
}

\author{
LUXURY, POWER AND MAGNIFICENCE \\ IN THE HOUSE AND COURT OF JUAN \\ DE LA CERDA Y VIQUE, II DUKE OF MEDINACELI \\ (1485-1544)
}

RAÚl ROMERO MEDINA

Universidad Complutense de Madrid

https://orcid.org/0000-0001-6129-1399

RESUMEN: El presente estudio aborda la Casa y Corte de don Juan de la Cerda, II Duque de Medinaceli (1485-1544), como espacio para mostrar el lujo, el poder y la magnificencia en el contexto de la monarquía habsbúrgica. Es en este marco en el que el linaje de La Cerda hizo uso de las formas artísticas para construir mediante los objetos suntuarios, joyas, orfebrerías, tapices, vajillas o muebles, una imagen de poder en sus señoríos nobiliarios, especialmente en el marquesado de Cogolludo y en el ducado de Medinaceli.

Palabras clave: Casa y Corte, Juan de la Cerda, monarquía habsbúrgica, magnificencia, poder, ducado de Medinaceli.

Este trabajo participa de los proyectos de investigación I+D «Corte y cortes en el Tardogótico Hispano. Narrativa, memoria y sinergias en el lenguaje visual». Ref.: PGC 2018-093822-B-I00 y «Espacios del coleccionismo en la Casa de Austria 2: siglos Xvi y XVII». Ref.: HAR2017-83094P. 
ABSTRACT: This paper shows the House and Court of Don Juan de la Cerda, II Duke of Medinaceli (1485-1544), as a space to display luxury, power and magnificence in the context of the Habsburg monarchy. Within this framework, the lineage of La Cerda made use of artistic forms to exhibit, through luxury objects, jewelry, goldsmiths, tapestries, tableware or furniture, an image of power in their noble lordships, especially in the Marquisate of Cogolludo and in the duchy of Medinaceli.

Keywords: House and Court, Juan de la Cerda, Habsburg monarchy, magnificence, power, duchy of Medinaceli.

\section{INTRODUCCIÓN}

«[...] Acordandome de la merced que (Dios) me hizo sin ser yo merecedor de ponerme en la grandeza y estado en que me ha puesto la qual me obliga que pues en esta vida presente he vivido como señor y caballero $[\ldots] »^{1}$.

Estas fueron las palabras con las que el II Duque de Medinaceli, Juan de la Cerda y Vique (1485-1544) encabezó el testamento que redactó en su palacio de Cogolludo, el 18 de enero de 1544. Este prócer falleció dos días más tarde y dejó atrás un largo servicio a la Corona, como miembro del Consejo Real, que le permitió ser reconocido por el emperador Carlos V como uno de los Grandes de España (1520) y tener para su primogénito el título de marqués de Cogolludo (1530). ${ }^{2}$ Su vida como señor y caballero sintetizan el concepto de nobleza de la época, vinculado de forma directa al término aristotélico de magnificencia, ${ }^{3}$ que obligaba a construir narrativas visuales de propaganda y legitimación.

Como descendientes de la Casa Real, ${ }^{4}$ el linaje de los de La Cerda tuvo una importante relevancia, influencia, así como conexiones políticas en la Castilla bajomedieval, que necesitaron de una estructura de Casa y Corte, un espacio curial que ya aparece perfectamente articulado con el I Duque de Medinaceli, Luis de la Cerda y de la Vega (c. 1442-1501) aunque pudo

1. Archivo Ducal de Medinaceli (adM), Sección Medinaceli, leg. nº. 7, doc. 11. Los paréntesis son nuestros.

2. Antonio Sánchez GonzÁlez: «Don Juan de la Cerda, un portuense al frente de la Casa de Medinaceli», Revista de Historia de El Puerto, 29, 2002, pp. 26-29.

3. Antonio Urquízar Herrera: «Teoría de la Magnificencia y teoría de las señales en el pensamiento nobiliario español del siglo XVI», Ars Longa, cuadernos de Arte, 23, 2014, pp. 93-111.

4. Francisco Fernández de Bethencourt: Historia genealógica y heráldica de la monarquía española. Casa Real y Grandes de España, Fabiola de publicaciones, Sevilla, 2003, pp. 12-18. 
tener su origen con el III Conde de dicho título, Luis de la Cerda y Mendoza $(+1443) .^{5}$

Como se ha señalado, el espacio curial no se restringió en exclusiva al ámbito del poder regio, pues hubo otros marcos curiales distintos del regio como pudieron ser los episcopales, arzobispales, de órdenes militares o nobiliarios. ${ }^{6}$ El linaje de los de La Cerda desarrolló una compleja estructura como Casa y Corte que parece parangonable a la de otros linajes contemporáneos como los Guzmanes, duques de Medina Sidonia ${ }^{7}$ o los Ponce de León, duques de Arcos de la Frontera ${ }^{8}$, cuyos casos han sido estudiados.

En unos momentos en los que la Corte se encuentra itinerante, las que podemos llamar como cortes satélites, es decir, aquellas casas nobiliarias que giraban en torno al poder regio como cortesanos, emprenden desde mediados del siglo XV la construcción de importantes y suntuosos palacios, ${ }^{9}$ que no son solo el reflejo del confort que requiere una época «moderna», sino que se concibieron como espacios para expresar el poder. Así, se ha señalado que la arquitectura bajomedieval estuvo dotada de un fuerte carácter identitario, el cual fue buscado intencionadamente por los promotores y vehiculado a través de la propia imagen del edificio. $^{10}$

La cada vez más compleja estructura de una Casa y Corte necesitaba de espacios adecuados para construir esas narrativas visuales de propaganda y legitimación. No resulta casual que dos de los miembros del linaje de La Cerda que articularon la estructura de la Casa de Medinaceli, el III Conde de Medinaceli y el I Duque de dicho título, fuesen los promotores respectivos de los dos palacios más importantes que tuvo el linaje en Castilla, el de la villa de Medinaceli y el de la villa de Cogolludo. ${ }^{11}$ (Figura 1 )

5. Raúl Romero Medina: La promoción artística de la Casa Ducal de Medinaceli. Memoria visual y arquitectura en Andalucía y Castilla (siglos XIV-XVI), Ediciones Doce Calles, Madrid, 2021, en prensa.

6. La bibliografía es bastante extensa pero un panorama actual de las investigaciones de la Casa y Corte se ofrece en Francisco de Paula Cañas Gálvez y José Manuel Nieto Soria: Casa y Corte. Ámbitos de poder en los reinos hispánicos durante la Baja Edad Media (1230-1516), La Ergástula, Madrid, 2019.

7. Miguel Ángel Ladero Quesada: La Casa Ducal de Medina Sidonia en Sevilla y su reino (12821521), Dykinson, Madrid, 2015.

8. Juan luis Carriazo Rubio: «La casa y corte de los señores de Marchena a finales de la Edad Media», en Francisco de Paula Cañas Gálvez y José Manuel Nieto Soria (coords.): Casa y Corte. Ámbitos de poder en los reinos hispánicos durante la Baja Edad Media (1230-1516), La Ergástula, Madrid, 2019, pp. 207-231.

9. Joaquín Yarza Luaces: La nobleza ante el Rey. Los grandes linajes castellanos y el arte en el siglo XV, Fundación Iberdrola, Madrid, 2003.

10. Javier Martínez de Aguirre: «Imagen e identidad en la arquitectura medieval hispana: carisma, filiación, origen y dedicación», Codex Aqvilarensis, 31, 2015, pp.121-150.

11. Raúl Romero Medina: «El palacio de Cogolludo en contexto: una residencia para la Casa y Corte del duque de Medinaceli a finales del siglo xv», Lexicon. Storie e Archittetura in Sicilia, 2021, en prensa. 


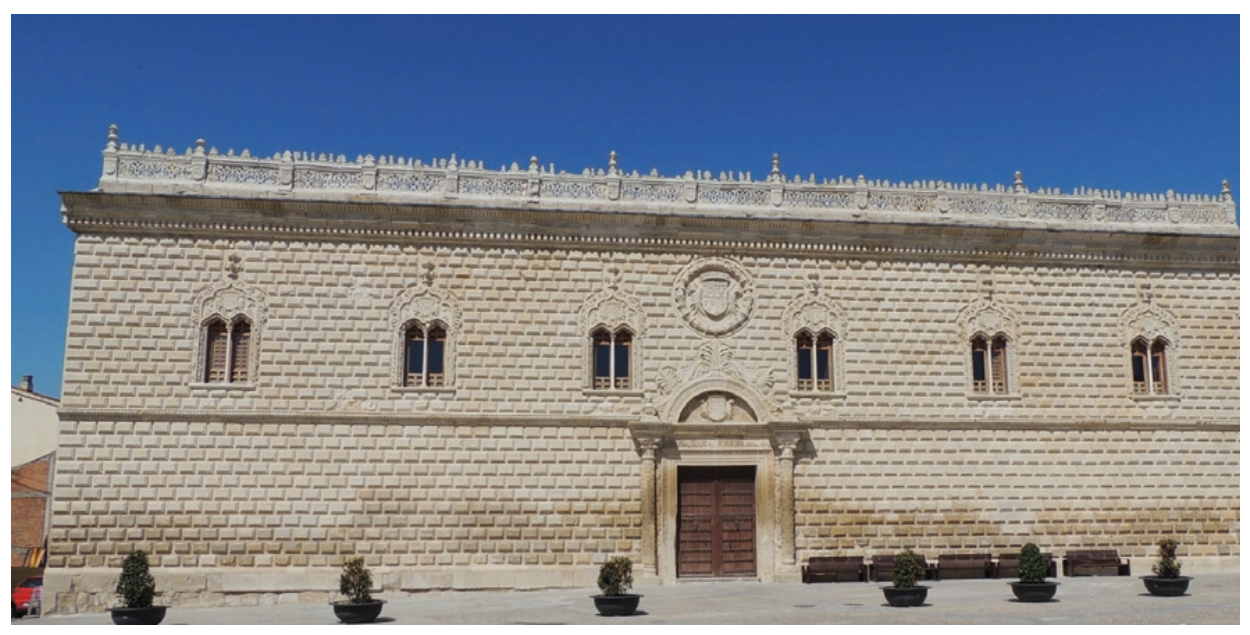

Figura 1. Palacio de Cogolludo, Guadalajara, ¿Lorenzo Vázquez de Segovia? c. 1490

Fue en estos marcos arquitectónicos en los que se hizo uso de unos objetos suntuarios tales como tapices, joyas, vajillas, orfebrerías, etc., trasladados de un lugar a otro con el señor de la casa, que necesitaron de un conjunto de servidores que los acomodaran y mantuvieran. Así, no se puede concebir el uso y la exhibición de las vajillas de plata y oro sin la figura del repostero de plata, el empleo de los cojines en habitaciones y estrados sin la presencia de los pajes, el aderezo de los caballos sin los mozos de cuadra o el traslado de estas piezas sin la presencia del acemilero mayor, por poner solo unos ejemplos. Es por ello por lo que, en mi opinión, resulta indispensable abordar el estudio de una determinada Casa y Corte desde un punto de vista holístico, pues ni se trata de estudiar las piezas artísticas descontextualizadas, ni de presentar solo la relación de servidores, pues aporta escaso valor en términos interpretativos o de la relevancia que tuvieron estas piezas como «artefactos culturales». ${ }^{12}$ Además, resulta necesario acercarse a este fenómeno desde un punto de vista transgeneracional, pues muchas de estas piezas tuvieron un valor material e inmaterial con capacidad para conectar a los miembros del linaje con sus antepasados cercanos o remotos. ${ }^{13}$

12. A propósito del debate sobre los usos artísticos de este tipo de artefactos culturales y su finalidad suntuaria-coleccionista puede consultarse ANTONio Urquízar Herrera: Coleccionismo y nobleza. Signos de distinción social en la Andalucía del Renacimiento, Marcial Pons, Madrid, 2007 y Roberto GonzÁLez Ramos: «Imágenes, libros y armas. Tipología y significado de los bienes de Diego Hurtado de Mendoza, conde Saldaña y marqués de Cenete (1520-1560)», Anuario del Departamento de Historia y Teoría del Arte, 21, 2009, pp. 31-46.

13. Algo que abordo en Raúl Romero Medina: «La promoción artística...», en prensa. 
Como en reiteradas ocasiones se ha señalado, la importancia de estos objetos suntuarios residía en el valor que marcaban en la balanza, ${ }^{14}$ en su tiempo de ejecución, pero también es verdad que muchos de ellos contribuían a generar narrativas de poder y fueron tan apreciados que comenzaron a ser anclados a los bienes del mayorazgo. ${ }^{15}$ En el contexto del Renacimiento habsbúrgico de las artes, al decir de Checa, ${ }^{16}$ no solo fueron las piezas que más se «coleccionaron», sino a las que se les dio mayor valor, lo que indiscutiblemente cuestiona el canon vasariano de las Artes. ${ }^{17}$

El objeto de este trabajo es poner en valor el conjunto de piezas que tuvo don Juan de la Cerda y Vique, II Duque de Medinaceli, para mostrar el lujo, el poder y la magnificencia en el contexto de su Casa y Corte. De hecho, partimos de la hipótesis que sostiene que la mayor parte de los gastos de la Casa estaban relacionados con el ejercicio de la vida cotidiana en palacio, gasto muy por encima del derivado de la administración de los estados patrimoniales: justicia, administración del derecho, gestión económica, etc. Dicho de otro modo, el gasto superfluo y la ostentación eran la norma de vida y en ello tuvo mucho que ver el consumo de piezas artísticas y los servidores que las ponían en uso y en valor. Por último, hemos de señalar que las fuentes documentales no nos permiten extraer conclusiones sobre otros objetos artísticos que pudo poseer el linaje en estos momentos, tales como pinturas o esculturas, siendo reseñados en los inventarios a partir de la segunda mitad del siglo XVI. ${ }^{18}$

Para contribuir al objetivo y corroborar la hipótesis de partida, analizamos la documentación inédita relativa a las cuentas de Jerónimo López, su oficial de cámara, para el período de $1534-1535,{ }^{19}$ su testamento de $1544,{ }^{20}$ la

14. Miguel Ángel Zalama Rodríguez: «La corona y el collar de Isabel la Católica y la financiación del I Viaje de Colón», en Jesús Valera Marcos y María Montserrat León Guerrero (coords.): Actas del Congreso Internacional V Centenario de la Muerte del Almirante, Universidad de Valladolid, Valladolid, 2006, pp. 305-314.

15. Como ocurrió con el caso de las tapicerías, Miguel Ángel Zalama Rodríguez: «Dejo y mando graciosamente al dicho príncipe todas las tapicerías. Felipe II y su interés por los tapices», en ÍDEM (coord.): El legado de las obras de arte: tapices, pinturas, esculturas... sus viajes a través de la historia, Universidad de Valladolid, Valladolid, 2017, pp. 203-221.

16. Fernando Checa Cremades: Renacimiento habsbúrgico. Felipe II y las imágenes artísticas, Universidad de Valladolid, Valladolid, 2018.

17. Una revisión sistemática del llamado canon vasariano de las artes en MATTEO MANCINI (ed.): Memoria. Historia y espacios del Arte en el tiempo de los Habsburgo a través de archivos e inventarios, Sílex, Madrid, 2020.

18. Una aproximación a la colección de retratos del linaje en el siglo XVI en Raúl RomERo MEDINA: «Il taisent la mémoire à la postérité» La galerie des portraits des ducs de Medinaceli dans le contexte du collectionisme des Habsbourg, Revue de l'Art, 212, 2021-2, pp. 11-23.

19. АDM, Sección Medinaceli, leg. $\mathrm{n}^{\circ} .68$, doc. 7.

20. ADM, Sección Medinaceli, leg nº. 7, doc.11. 
almoneda de sus bienes de $1549^{21}$ y otros documentos que ya se han dado a conocer y que serán citados de forma pertinente. ${ }^{22}$

\section{ESTRUCTURA DE LA CASA Y CORTE DEL DUQUE DON JUAN}

Como hemos señalado, las nóminas conservadas de las cuentas de Jerónimo López, oficial de cámara del duque don Juan, para el periodo de 1534-1535, nos permiten conocer de forma clara la estructura de su Casa. Así, esta podría dividirse, por un lado, en lo relacionado con la administración de los estados ${ }^{23}$ (caballeros, alcaides, escuderos, monteros, montaraces, guardias, letrados y procuradores $)^{24}$ y lo tocante a la vida cotidiana en palacio, que estaría formada por familiares ${ }^{25}$ oficiales, otros oficiales, reposteros, trompetas, cazadores, pajes, otros oficiales, mozos de espuelas y hombres de pie. En cualquier caso, hemos de considerar que en la práctica la división entre Casa y administración no fue tal.

Hay que tener en cuenta que las nóminas reflejan que había cortesanos que eran pagados durante todo el año y otros que cobraban por trabajos a tiempo parcial o a los que se les abonaba cierta cantidad de maravedíes por servicios puntuales. En total, estamos hablando del orden de 300 personas, una cifra que nos muestra la importancia de esta Casa y Corte si la comparamos con el número de componentes de la Corte de Borgoña que indicaba la Ordenanza de 21 de junio de 1517 , es decir, $608 .^{26}$

21. AdM, Sección Medinaceli, leg. $\mathrm{n}^{\circ} .102$, doc. 6 .

22. Raúl Romero Medina: «Plateros tardogóticos de Valladolid al servicio de la Casa Ducal de Medinaceli. A propósito de ciertas joyas para doña María de Silva y Toledo», Espacio, Tiempo y Forma, Serie VII, 6, 2018, pp. 259-280.

23. Algunos de ellos servían también en el palacio como fue el caso de Hernando de Torres que era camarero del duque y al mismo tiempo tenía la tenencia del castillo de Medinaceli. AdM, Sección Medinaceli, leg. 68 , doc. 7 .

24. Por ejemplo, los caballeros, alcaides y escuderos eran 76, 4 los montaraces y guardias (Andrés de Padilla, Hernando de Heredia, Cristóbal de Benavente y Sancho Aguilar), 13 los monteros (Juan Delgado, Antón Alonso, Juan Montero, Juan Criado, Francisco Tarín, Miguel Romero, Miguel de la Cuesta, Aparicio, Juan Tundidor, Baena, Juan Romero, Robres y Antón de las Heras) y 10 los letrados y procuradores (doctor Esportillo, doctor Bravo, doctor Espinosa, licenciado Morales, licenciado Bastida, licenciado Espinosa, licenciado Buitrón, Francisco de Valladolid, López del Burgo y Gamarra). AdM, Sección Medinaceli, leg. 68 , doc. 7.

25. Aunque las amas de cría estén recogidas en una relación aparte, hay que señalar que eran consideradas como miembros de la familia. Así, sabemos que María de Escalante fue el ama de cría del marqués de Cogolludo, don Luis de la Cerda, y que Catalina de Medina y Elena de Medina lo fueron respectivamente de doña Isabel de la Cerda, que casaría con el comendador de Torrova de la Orden de Calatrava, y de don Gastón de la Cerda, quién llegaría a ser III Duque de Medinaceli. AdM, Sección Medinaceli, leg. 68, doc. 7.

26. Sobre este asunto puede consultarse el trabajo de RAYMOND. P. FAGEL: «Poner la Corte en orden, poner orden en la Corte. Los cambios en la Casa de Borgoña alrededor del primer viaje hispánico de Carlos $\mathrm{V}$ (1515-17)», en José Eloy Hortal Muñoz y Félix Labrador Arroyo (ed.): La Casa de Borgoña. La Casa del Rey de España, Leuven University Press, Louvain, 2014, pp. 51-72. 
Es en la nómina relacionada con la vida cotidiana en la que podemos distinguir los diferentes oficios repartidos en el ámbito curial, aquellos que podríamos denominar de cámara (físico, barbero, cocinero, cirujano, boticario, despensero, repostero, trinchante, maestresala, caballerizo, paje, etc.), de capilla (capellanes, clérigos y mozos) y los vinculados con su seguridad (mozos de espuelas y hombres de pie). Hay otras nóminas que reflejan pagos a caminos, ${ }^{27}$ continos, ${ }^{28}$ a un médico ${ }^{29} \mathrm{o}$ a un truhan, ${ }^{30}$ por citar solo algunos ejemplos. Estos también deben de ser considerados como oficiales de la Casa del duque Juan de la Cerda. (Apéndice 1).

Las nóminas nos permiten conocer las jerarquías áulicas, pero lo que nos interesa destacar es que del total de 3.239.819 maravedíes que hubo de gasto para el período de 1534-1535, más de dos millones de maravedíes fueron destinados a sufragar los gastos de la vida cotidiana en palacio. ${ }^{31}$ (Gráf. 1).

Como tendremos ocasión de demostrar, el importante uso que hizo el duque don Juan de las piezas de lujo relacionadas con la idea de expresión del poder y de la magnificencia, es directamente proporcional al número de servidores de cámara que ejercían oficios relacionados con su mantenimiento y puesta en escena. Así, nos encontramos con dieciséis reposteros, que eran los encargados de la custodia de los objetos pertenecientes a la cama, al estrado, etc. La figura del repostero de plata corrobora la existencia de un oficial encargado de la vajilla y de otras piezas de plata que solían estar a cargo del camarero. Junto a ello, la contabilización de dieciocho pajes (de copa, de cámara y de otros servicios) y un elevado número de mozos (plata, capilla, cocina, etc.) explican el importante trajín diario de la vida en palacio.

27. «Que distes mas a Fabian de Bretes de un camino que hizo a la corte por mi mandado por el mes de agosto de veynte y seys dias a çinquenta maravedies cada día myll e trezientos e çinquenta maravedies I U CCCL». "Que distes mas a Diego de Vega para llevar a Laynez para lo del pleyto de Luzon myll e çiento e veynte e çinco maravedies I U CXXV». Y muchos casos más... AdM, Sección Medinaceli, leg. 68, doc. 7.

28. «Françisco Hernandez veçino de Guadalaxara a de aver este dicho año de raçion e acostamyento dende doze de abril que le mande asentar en mys libros por contino de mi casa a raçon de veynte myll maravedíes por año cartoze myll y trezientos y sesenta y siete maravedíes XIIII U CCCLXVII (Visto en $\mathrm{p}^{\circ}$ de todas estas partidas exçepto las que estan cargadas y glosadas)».«Carryllo a de aver sobre los veynte y tres myll maravedíes que llevaba por contino de my casa dende nueve de henero que le mande a trezientas myll maravedies novesientos y setenta y siete maravedies DCCCCLXXVII» ADM, Sección Medinaceli, leg. 68, doc. 7.

29. «El doctor Royo medico de esta my villa a de aver dende mediado el mes de julio del año que paso de myll e quinientos e treynta e tres años fasta en fin de diciembre de quinientos e treynta e quatro años que son un año qunplido y çinco meses y medio a raçon de çinco myll maravedíes cada año porque que en palacio como los otros médicos lo an acostumbrado hazer siete myll e çiento y ochenta y siete maravedíes e medio VII U CLXXXVII m». AdM, Sección Medinaceli, leg. 68, doc. 7.

30. «Que distes mas por mi mandado a Calabaça truan dos ducados que le hiçe merçed DCCL». ADM, Sección Medinaceli, leg. 68, doc. 7.

31. AdM, Sección Medinaceli, leg. 68, doc. 7. 


\section{Gastos en maravedíes de la Casa y Corte de Juan de la Cerca, II Duque de Medinaceli, Período 1534-1535}

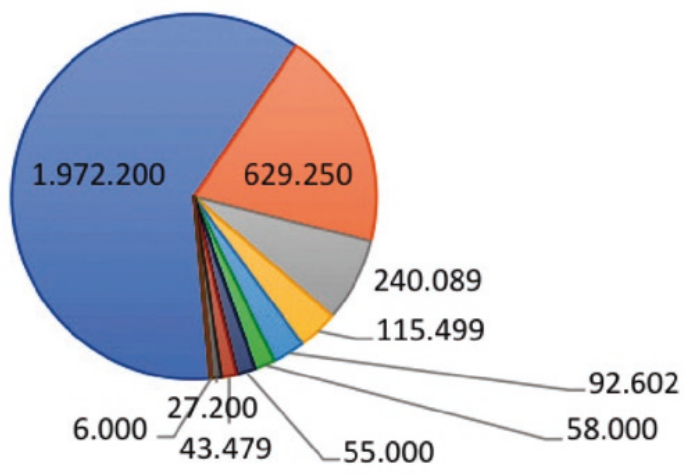

$\square$ Personal de Casa y Corte

$\square$ Juros y mercedes

$\square$ Otras partidas

$\square$ Monteros

Amas de cría y lavandera $\square$ Caballeros, alcaides y escuderos

$\square$ Otro asuntos

$\square$ Letratos y procuradores

$\square$ Otro personal de Casa y Corte

$\square$ Montaraces y guardias

Gráfico 1. Reparto del gasto de la Casa y Corte en 1534-1535 de un total de 3.239.819 mrs

Como veremos, la caballeriza era fundamental en la exhibición del poder y los arreos, jaeces, cabezadas, tiros, jáquimas, con las que se llevaban a los caballos, o las sillas de montar, eran piezas realizadas con materiales de lujo como el oro, la plata, los esmaltes, el cuero, el cordobán o los terciopelos. Un buen número de oficiales estaban dedicados a la caballeriza ducal.

Las actividades cinegéticas generaban la confección de piezas importantes, nada se escatimaba en lo referente al lujo. La afición de don Juan de la Cerda por la caza se refleja en la nómina de servidores donde se asienta a catorce personas relacionadas con esta actividad cortesana.

La puesta en escena y los abultados séquitos ducales se hacen evidentes en la figura del macero, del atabalero o de los diez trompetas con los que se contribuía a magnificar la imagen pública del duque durante sus viajes o las entradas en las ciudades o villas por donde pasaba. No cabe duda de que estos «trompetas» jugaron un papel destacado desde una perspectiva heráldica, como se ha puesto de relieve en los actos reales y de la nobleza en Castilla. ${ }^{32}$

32. Francisco de Paula Cañas Gálvez: «La cámara de Juan II: vida privada, ceremonia y lujo en la Corte de Castilla a mediados del siglo XV», en ANDRÉs GAMBra GUTIÉRREZ y FÉLIX LABRADOR ARROYO (coords.): Evolución y estructura de la Casa Real de Castilla, Polifemo, Madrid, 2010, pp. 122-123 y p. 152. 
Además, para la puesta en escena en las fiestas y ceremonias que habitualmente se acompañaban de justas y torneo ${ }^{33}$ había que presentarse magníficamente vestido, lo que explica que las nóminas recojan la figura de sastres ${ }^{34}$ calceteros $^{35}$ o zapateros.

Por último, no menos importancia tenía el servicio de cocina y mesa en el que las mantelerías, las cuberterías y las vajillas, casi siempre expuestas en el mueble aparador, jugaron un papel destacado. Era aquí donde entraban en juego un importante número de servidores tales como el cocinero, el botiller o el despensero y otros importantes oficiales. Así, por ejemplo, el II Duque de Medinaceli tuvo a su servicio dos maestresalas, dos trinchantes y un paje de copa. Numerosas miniaturas francesas que reflejan los ambientes de la corte del duque de Borgoña o del duque de Berry presentan estos muebles aparadores que mencionamos o mesas suntuosas asistidas por el personal de servicio. (Figura 2)

Estos servidores llegaron a tener tal fama que incluso se solía recurrir a ellos con motivos de celebraciones especiales, como fue el caso de Oviedo, un reputado cocinero del conde de Monteagudo, a quien se invitó para que fuese al palacio de Medinaceli a "guisar quando vino el rey». ${ }^{36}$ En esta ocasión de entre 1534 y 1535 el emperador Carlos V comió salmones. ${ }^{37}$ Efectivamente, las fuentes corroboran que el rey estuvo en Medinaceli desde el sábado 24 de enero de 1534 al domingo 25, en que partió para Sigüenza. ${ }^{38}$ También realizó una estancia desde el sábado 6 de marzo de 1535 al martes $9 .{ }^{39}$ Por ello, las cuentas podrían referirse a una de estas dos visitas o a las dos, pues el registro de pago a Gerónimo de Torralva señala que yva por salmones ${ }^{40}$ lo que denota que era una acción frecuente, por otro lado.

No obstante, no había sido la primera vez, pues constan visitas anteriores y posteriores del emperador a Medinaceli. De entre las anteriores a 1534-

33. Sobre el papel que tenían estos juegos caballerescos para exhibir el lujo y la magnificencia de forma pública, véase el interesante texto de Jesús Félix Pascual Molina: «Magnificencia y poder en los festejos caballerescos de la primera mitad del siglo XVI», en InMACulada RodríGuez Moya y Víctor Mínguez (dirs.): Visiones de un Imperio en fiestas, Fundación Carlos de Amberes, Madrid, 2016, pp. 121-143.

34. Eran tan importantes que además de entrar en nómina se podían contratar de lugares no generalmente próximos, como fue el caso de los sastres que el duque mandó buscar a Valencia. «Que distes por mi mandado a Geronimo Ropiñon del alquiler de sus mulas quando fue a Balençia a por los sastres diez y siete reales que montan quinientos y setenta e ocho maravedies D LXXVIII» ADM, Sección Medinaceli, leg. 68, doc. 7.

35. « $\mathrm{R}^{\circ}$ de Rodrigo Alvarez my calzetero a de aver este dicho año de rason e costamyento dende veynte y siete de henero que le mande asentar en mys libros a razón de dos myll maravedies por año myll e ochocientos e quarenta e nueve maravedies e medio I U DCCCXLIXmº (po por su libro)». AdM, Sección Medinaceli, leg. 68, doc. 7.

36. Servicio por el que se le pagó cuatro ducados, es decir, la importante cifra de 1.500 maravedies. ADM, Sección Medinaceli, leg. 68, doc. 7.

37. «Que distes mas a Geronimo de Torralva que yva por salmones quando vyno el rey un ducado CCCLXXV». ADM, Sección Medinaceli, leg. 68, doc. 7.

38. Manuel de Foronda y Aguilera: Estancias y viajes del Emperador Carlos $V$ desde el día de su nacimiento hasta el de su muerte[...], s.l; s.n, 1914, p. 384.

39. Ibidem, p. 401.

40. AdM, Sección Medinaceli, leg. 68, doc. 7. 
1535 se registran las siguientes: el jueves 30 de julio de 1528 comió, cenó y pernoctó en esta villa y el 31 de julio, después de comer, marchó para Sigüenza. ${ }^{41}$ Del mismo modo, el martes 16 de marzo de 1529, había cenado y pernoctado en Medinaceli y, tras almorzar, al día siguiente marchó para Eriza. ${ }^{42}$ Entre las posteriores, el rey pernoctó en Medinaceli el martes 6 de marzo de 1543, siendo recibido por el duque don Juan y la duquesa doña María. ${ }^{43}$

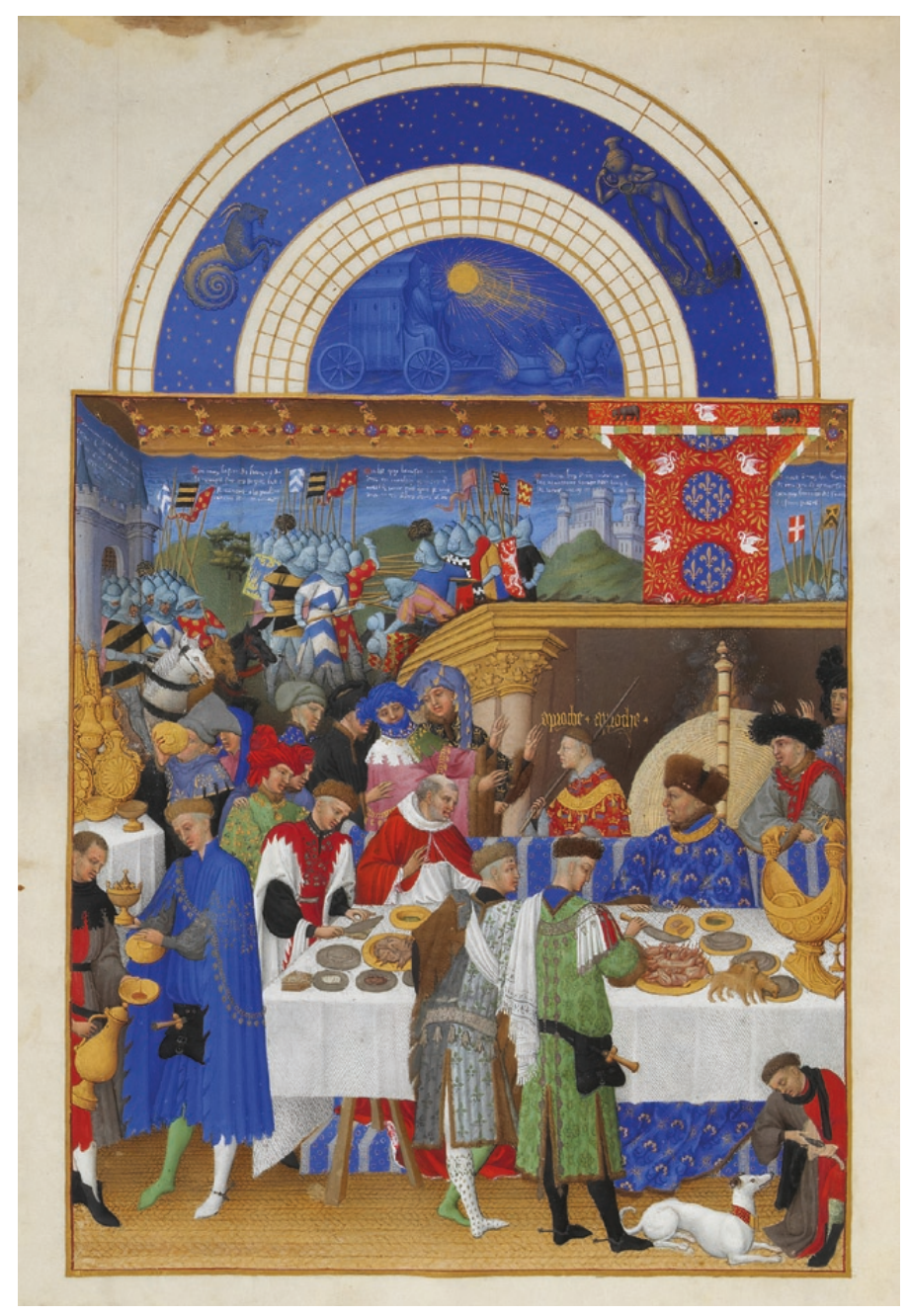

Figura 2. «Mes de enero», Muy Ricas Horas del duque de Berry, Hermanos Limbourg. c. 1412-1416, Bibliothèque du Château de Chantilly, Ms. 65, fol. 1v
41. Ibidem, p. 312.
42. Ibidem, p. 322.
43. Ibidem, p. 541. 


\section{LOS OBJETOS DE LA MAGNIFICENCIA}

Los artefactos que tuvo el II Duque de Medinaceli responden muy bien a ese mundo cortesano de la magnificencia definido por G. B. Pontano, ${ }^{44}$ siguiendo los escritos de Aristóteles. Estos objetos parecen sacados literalmente de su De Splendore al mencionar objetos espléndidos, útiles, aquellos que no pierden su valor de lujo, los suntuarios y los de apparatu dicemus. Exceptuando estos últimos, la mayoría están bien representados en la cámara del de Medinaceli.

Así, la presencia de objetos útiles (supelectile), tales como platos, vasos, telas o suntuarios (ornamenta), es decir, joyas, tapices o artefactos moriscos, releva un sistema de las artes y de patrocinio artístico más «suntuario» que propiamente coleccionístico, aspecto evidente teniendo en cuenta, además, el período en el que nos situamos, es decir, la Europa de Carlos V y la familia imperial. ${ }^{45}$

La inversión en piezas de oro y plata era una rentabilidad sobre todo en momentos de falta de liquidez, ya que estos objetos se podían vender o pignorar. Es por ello por lo que se tenía un estricto control sobre estas piezas y la prueba es evidente en el testamento del II Duque (1544) cuando perdona a su repostero de plata Juan Cavallo o Caballero por «tres platos de plata y un candelero de plata $»^{46}$ que le habían hurtado «la pasada que su Magestad paso por Medinaçeli». ${ }^{47}$ Sabemos que especialmente el palacio de Cogolludo estuvo equipado con un magnífico ajuar de plata que el I Duque de Medinaceli, Luis de la Cerda y Mendoza, había comprado a varias plateros a los que pagó, entre 1496 y 1498, casi un millón de maravedíes. ${ }^{48}$ Además de en su cámara, los duques de Medinaceli depositaron importantes cantidades de plata en el monasterio de Santa Isabel de Medinaceli.

En cualquier caso, muchas de estas piezas eran vendidas en las almonedas para saldar las deudas de la Casa. En el caso del II Duque de Medinaceli, conocemos una de las almonedas, la que se hizo en Medinaceli el 13 de septiembre de $1549 .{ }^{49}$ En ella se vendieron piezas 236.

44. Giovanni Battista Pontano: I libri delle virtù, F. Tateo (ed.), Bulzoni, Roma,1999, pp. 228-

45. Fernando Checa Cremades: Los inventarios de Carlos V y la familia imperial, Fernando Villaverde Ediciones, Madrid, 2010.

46. АDM, Sección Medinaceli, leg. 7, doc. 11.

47. AdM, Sección Medinaceli, leg. 7, doc. 11.

48. Raúl Romero Medina: «El palacio tardogótico castellano como arma de proyección social del linaje. Del Infantado a Cogolludo», Boletín de la Asociación de Amigos del Museo de Guadalajara, 6, 2015, pp. 57-74.

49. No obstante, por el valor que tuvo esta almoneda, es decir, 21.218,5 maravedíes, y por la fecha (cinco años después de su muerte) debió ser una segunda que debió celebrarse para saldar más deudas. ADM, Sección Medinaceli, leg. 102, doc. 6. La primera, la de Cogolludo, no ha llegado a nosotros. 
significativas que fueron adquiridas por uno de sus cortesanos, Bartolomé del Águila:

Yten se rematon dos flor de lis e media de plata e un cabo de una cuchara de plata e dos hebillas de plata e una concha de plata e un cuchillo con cabos de plata e un brocal de çinto de plata e una chapita de plata e una chapa de plata esmaltada tres sortijas de plata e un pedaço de un ducado de plata e un brocalico de plata con su cadenica de plata con un tarugo de plata que todo se peso e dixo el dicho platero que pesaban veynte e nueve reales a razon de a treinta y cuatro el real rematose en treinta e quatro e un reales en el dicho Bartolome del Aguila testigos dichos I U LIIII. ${ }^{50}$

Las joyas estuvieron muy presentes en la vida de don Juan de la Cerda, muchas de estas piezas construían la imagen artística del linaje y más en ese lujo de oro que experimenta el Renacimiento cortesano. Algunas de estas joyas se convirtieron en símbolos de identidad para el linaje y fueron heredadas de generación en generación. Así, por ejemplo, los joyeles de «la berenjena»o «la flor de lis» que menciona el I Duque de Medinaceli en 1499, fueron regalados por su hijo, el II Duque de Medinaceli, a su esposa, doña María de Silva, como ofrenda por cada uno de sus partos. ${ }^{51}$ Así, nombrar a las joyas fue señal de reverencia y aprecio hacia ellas, una costumbre que se observa en la Casa de Borgoña ${ }^{52}$ y que heredan los Habsburgo. ${ }^{53}$ Estos joyeles no han llegado a nosotros, pero el de «la berenjena» pudo estar compuesto de un enorme rubí formado por una perla irregular periforme, rematada con esmeraldas que generaban un tallo con tres hojas que evocaba ese fruto de la tierra, la berenjena, lo que revela cómo la joyería la empleaba por ser un elemento exótico de origen islámico. El retrato de dama de Scipione Pulzone (1585) muestra un joyel semejante que nos permite hacernos una idea de cómo pudo ser ese rubí de la berenjena. (Figura 3)

50. ADM, Sección Medinaceli, leg. 102. doc. 6.

51. Raúl Romero Medina: «Plateros tardogóticos de Valladolid...», pp. 259-280.

52. El duque de Berry tuvo un rubí llamado «Corazón de Francia» y Carlos el Temerario fue dueño de tres rubíes denominados como «Los tres hermanos». Peter Burke: «Renaissance jewels in their Social Setting», Princely Magnificence: Court Jewels of the Renaissance, 1500-1630, Carswell Legal Pubns, London, 1980, p. 8.

53. En 1509 el inventario de Juana de Castilla recogía el joyel «del Emperador» y en el inventario post mortem de su nuera, Isabel de Portugal, se habla de un broche llamado «el Serafín». Fernando CHECA Cremades: «Los inventarios de Carlos V...», pp. 918-921 y 1300. 


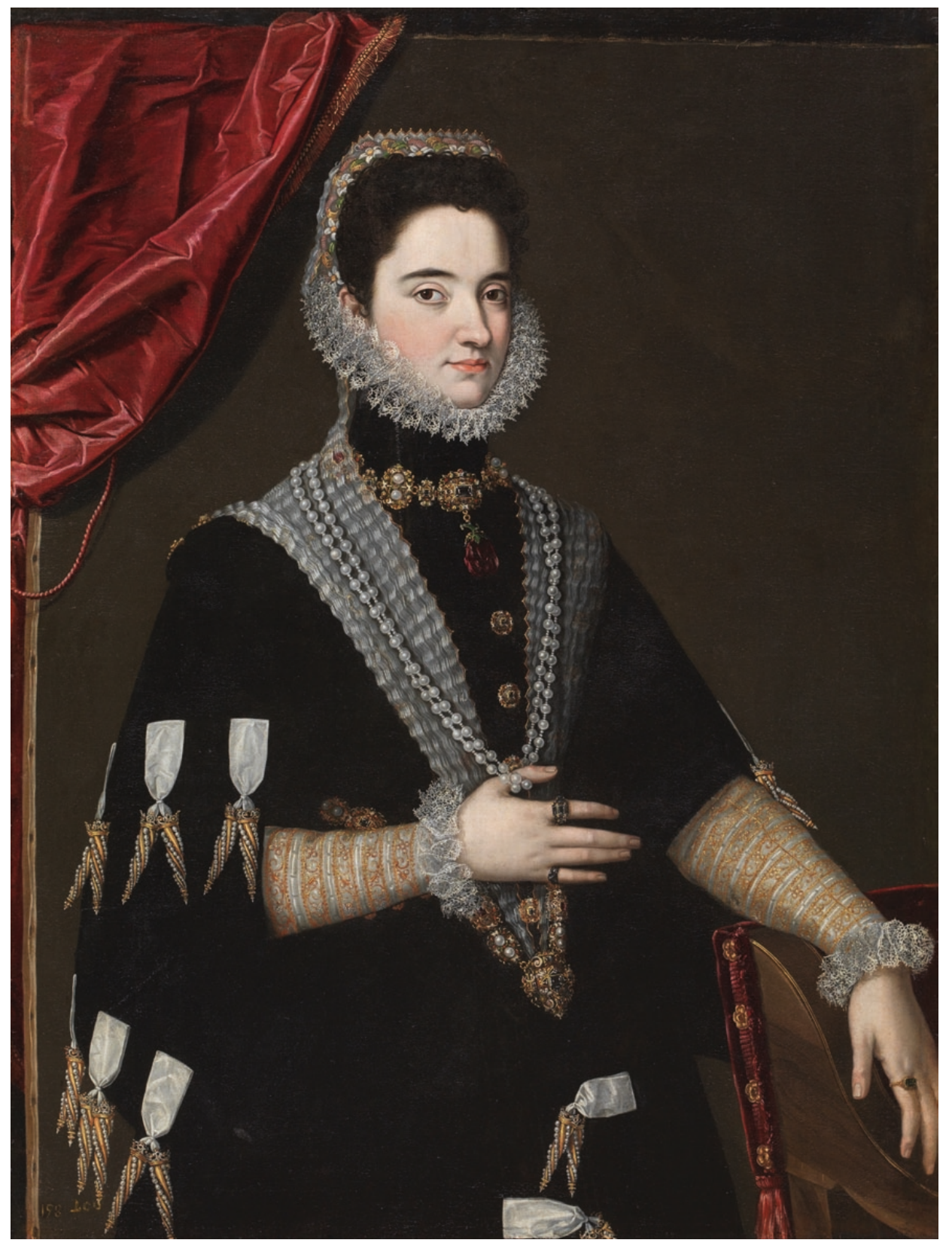

Figura 3. Retrato de Dama, detalle del joyel, Scipione Pulzone, 1585, 113 x $85 \mathrm{~cm}$, óleo sobre lienzo, Museo Nacional del Prado, Madrid. (Inv. P001029) 
Es evidente que muchos de estos joyeles sufrían cambios y añadidos según las modas, como el joyel de «la Rosa», cuya presencia en el linaje se rastrea desde 1499 a $1607,{ }^{54}$ que disfrutó el II Duque de Medinaceli. Fue una costumbre bien rastreada en el contexto de los Habsburgo hasta tal punto que ha permitido hablar de una "práctica de reciclaje», ${ }^{55}$ algo tan frecuente como la venta de estas joyas en las almonedas.

En la almoneda del II Duque de Medinaceli se vendieron muchas piezas de uso personal, así su secretario, Martín de Mondragón, afirmaba tener en su poder «un brazalete de hilo de oro e plata con seis ojales de oro pequeños con tres çintados azules e una leonada con sus clavos de oro pequeños e forrada en raso carmesi», ${ }^{56}$ una pieza que su señor le había entregado en Cogolludo. El brazalete se remató en el alcaide de Deza, Bartolomé del Águila, y alcanzó un valor de 750 maravedíes.

En la caballeriza del duque los objetos de plata y oro, así como los textiles, estuvieron muy presentes. Este era un espacio importante ${ }^{57}$ que estaba atendido por un número destacado de servidores, un caballerizo mayor, Martín de Salcedo, un caballerizo de mulas, Tormes, y un número muy considerable de mozos de caballos y espuelas (apéndice I). Su primogénito, el marqués de Cogolludo, disponía de caballeriza propia que estaba a cargo un tal Félix de Escobedo. ${ }^{58}$

Se han conservado documentos que prueban que el duque Juan de la Cerda compraba los mejores puras razas del mercado, por ejemplo, en 1520 adquirió para su caballeriza dos buenos caballos moriscos. ${ }^{59}$ En 1535 pagó a dos servidores, Juan de Morón y Aguilera, «para yr por las yeguas y un caballo que compró garañón», es decir, un semental de extraordinaria corpulencia que se les echaba a las yeguas para la procreación de mulas y de machos. ${ }^{60}$

A los caballos se les solía llevar con las mejores guarniciones y eran momentos importantes para mostrar la magnificencia cuando se hacía uso de ellos en las caballerías o en los torneos. No se escatimaba en gastos y en 1535

54. Raúl Romero Medina, «La promoción artística...», en prensa.

55. Juan Luis González García: «Prácticas de reciclaje y auto-consciencia familiar en el coleccionismo artístico de los Habsburgo", en Fernando Checa Cremades (dir.): Museo Imperial. El coleccionismo artístico de los Austrias en el siglo XVI, Fernando Villaverde Ediciones, Madrid, 2013, pp. 43-52.

56. AdM, Sección Medinaceli, leg. 102, doc. 6.

57. Las cuentas de 1534-1535 le dedican algunas entradas como «que distes mas a Garcia de Medrano del alquiler de la cavalleriça de mys mulas quatro ducados y a Tormes para adoballa ochoçientos e treynta e un marevedis II U CCCXXXI mº (cavallerizas de las mulas)». ADM, Sección Medinaceli, leg. 68. doc. 7.

58. «Primeramente que distes por mi mandado que hos lo envie mandar con Feliz Aescobedo cavalleriço del marques mi hijo de una trucha que me dio ducado e medio que vale quinientos e sesenta e

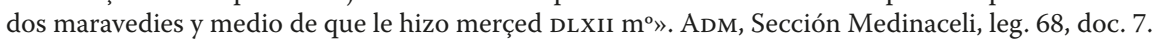

59. Raúl Romero MedinA, «La promoción artística...», en prensa.

60. AdM, Sección Medinaceli, leg. 68, doc. 7. 
Diego de Vega fue enviado a Valladolid para «traer seys guarniciones de caballos las dos doradas de terçiopelo y las dos de terçiopelo y las dos de quero y dos sillas de quartao y dos chapeos e unos de terçiopelo negro y el otro de terçiopelo pardo y espuelas». ${ }^{61}$ Todo ello costó 28.946 maravedíes puesto que también se aprovechó el viaje para traer «copas doradas y barniçadas y dos arquillas pequeñas en que venyan». ${ }^{62}$

En cualquier caso, hay que señalar que los contactos con Valladolid fueron constantes teniendo en cuenta que era uno de los principales centros plateros de Castilla, desplazando ya a Burgos en el siglo XvI, ${ }^{63}$ y allí se acudía para controlar los encargos y para tasar y marcar las piezas. Así lo hizo en 1513 Juan de Salazar, una suerte de solicitador o agente de negocios del duque, para controlar las piezas que se labraban para la duquesa María de Silva. ${ }^{64}$

En la almoneda de 1549 hay varios asientos relativos a guarniciones ${ }^{65} \mathrm{o}$ aciones, ${ }^{66}$ la correa fija de la que dependía el estribo en la silla de montar, guarnecidos de terciopelo, que salen a la venta. Aunque ninguna de estas piezas se han conservado, los retratos españoles contemporáneos de la familia imperial suelen mostrar estas piezas. Así, es significativo el retrato de Juana de Portugal realizado por Sánchez Coello en 1553 donde la princesa, que está encinta, sujeta unas riendas que forman los monogramas de ella y de su marido -Juan y Juana-. Se trata del último testimonio de su vida de casada, pues a inicios de enero de 1554 su marido fallecía como consecuencia de la caída de un caballo (figura 4).

La caza y la cetrería tenían un papel destacado en la diversión del duque Juan de la Cerda y a ello dedicó mucho tiempo y dinero, como lo prueba el hecho de que en las nóminas de la Casa se asienten pagos a catorce cazadores o los guardas de las distintas dehesas de las que gozó. La afición por los halcones, aves indispensables en la práctica de la cetrería, se hace evidente cuando en la almoneda del II Duque se remató una caja de herramientas de halcones llamada «herramental» y otras «syete pezezuelas de un aramental de alcones». ${ }^{67}$

61. ADM, Sección Medinaceli, leg. 68, doc. 7.

62. Adm, Sección Medinaceli, leg. 68, doc. 7.

63. Aurelio Barrón García: La época dorada de la platería burgalesa. 1400-1600, Diputación Provincial de Burgos, Valladolid-Burgos, 1998.

64. Raúl Romero Medina, «Plateros tardogóticos de Valladolid...», pp. 274-276.

65. «Yten se remato una guarniçion de terçiopelo negro vieja de caballo entretallada en quinze reales con un arpillera de bocaçi en un real en el dicho Bartolome del Aguila testigos dichos DXLIII (El dicho, guarniçion de cavallo)». AdDM, Sección Medinaceli, leg. 102, doc. 6.

66. «Yten se remataron unas açiones guarneçidas de terçiopelo viejas en un real en el señor don Diego de la Çerda testigos dichos pago a Mondragon XXXIIII (El señor don Diego, açiones p)». AdM, Sección Medinaceli, leg. 102, doc. 6.

67. ADM, Sección Medinaceli, leg. 102, doc. 6. 


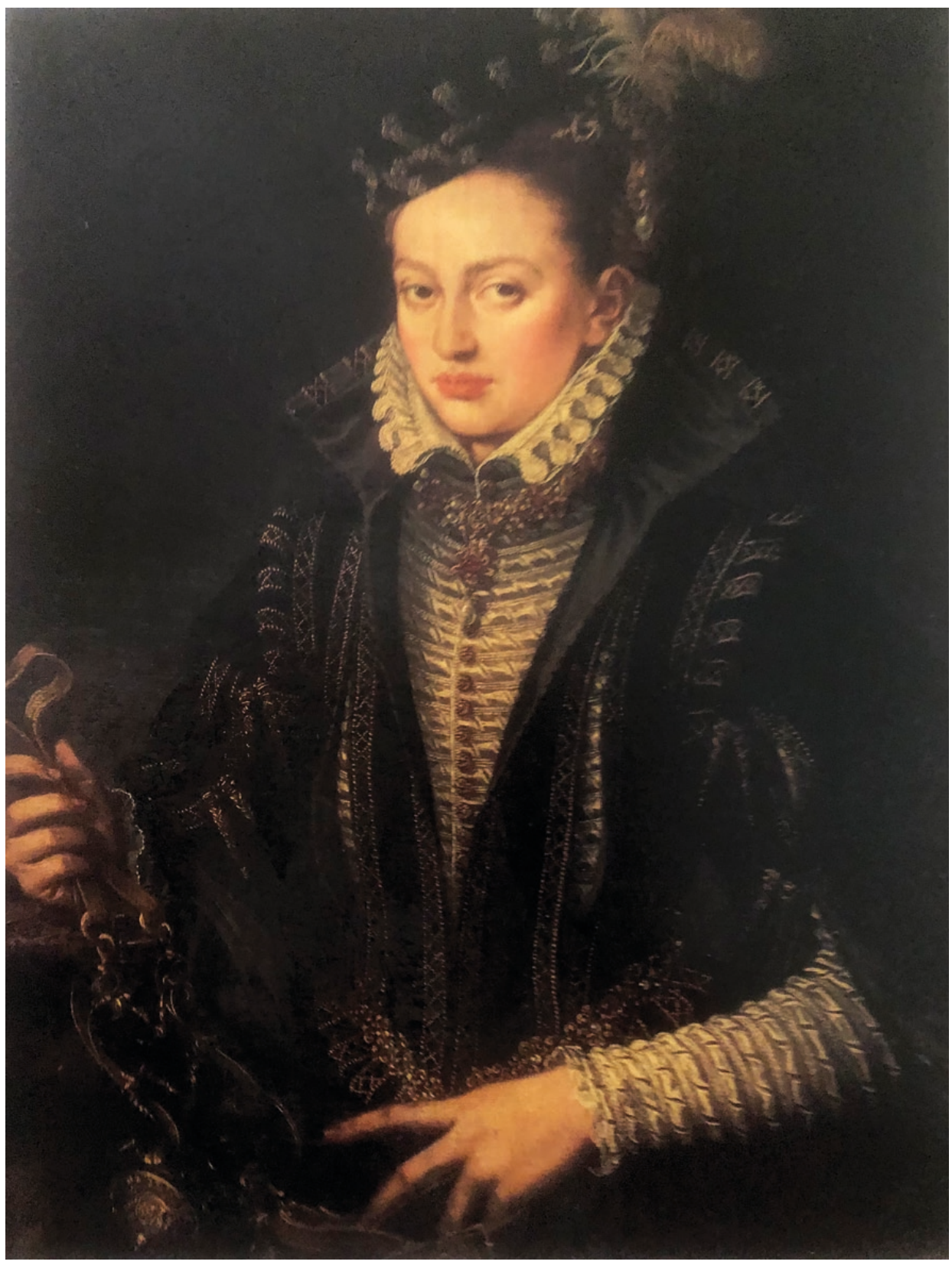

Figura 4. Retrato de Juana de Portugal, Alonso Sánchez Coello, 1553, óleo sobre lienzo, Embajada de Bélgica, Madrid 
La presencia de animales auxiliares para la caza se corrobora con los lebreles y galgos, animales por los que se pagaban importantes cantidades de dinero, como los 2.250 maravedíes que se le pagaron en 1535 a Juan de Tafalla «para ir por un galgo». Su propia manutención también implicaban altos $\operatorname{costes}^{68}$ y la presencia de servidores que se dedicaban a su cría. ${ }^{69}$ A estos animales se les llevaba con collarines de lujo ${ }^{70}$ y vemos por ejemplo cómo en el retrato de Doña Juana de Austria con dogo el animal se adorna con un collarín que porta las armas de Castilla y Portugal, en una sutil visualización de la alianza dinástica que reforzaba el poder de los Habsburgo, o en el del archiduque Alberto VII donde el dogo lo luce de terciopelo carmesí (figura 5).

La figura de un personaje como el duque Juan de la Cerda, que intervino en la guerra de Navarra (1512) y pacificó la revuelta de los Comuneros (15201522), explica la posesión de armas y armaduras tan útiles en estas actividades militares, pero al mismo tiempo para los pasatiempos caballerescos, con su uso como parte de la magnificencia cortesana. ${ }^{71}$ Sin embargo, es pronto para hablar de un afán coleccionístico ${ }^{72}$ y las piezas que recoge su almoneda así lo corrobora:

Yten se remataron quatro guantes e dos gorjales pequeños e dos gozetes e dos pedaços de malla e una braga de malla grosera e tres yerros de lanças de harmas el uno quebrado con su funda de cuero colorada y otro blanco e un beruelo de justa e una funda de sayas en Sancho de Ocaliz en seis ducados testigos dichos II U CC L (Malla, Sancho de Ocaliz). ${ }^{73}$

68. «Que distes mas por mi mandado a Juan de Tafalla para leche al lebrel un real xxxinI». AdM, Sección Medinaceli, leg. 68, doc. 7.

69. «Que distes mas por mi çedula y por my mandado a Juan Carnizero porque cria los lebreles tres ducados que montan myll e çiento e veynte e çinco maravedies I U CXXV». ADM, Sección Medinaceli, leg. 68, doc. 7 .

70. En la aludida almoneda de 1549 se venden varios collares de lebrel: «Yten se remato un collar de terçiopelo carmesi para un perro e una lonja de gavilan e veinte e çinco maravedies en el señor don Diego de la Çerda testigos dichos pago a Mondragon XXV (El señor don Diego, collar e lonja p)». «Yten se remato medio collar de lebrel y una funda de lienço de espada e dos cornezuelos de çorço dos yerros pequeños de señalar ganado e otros herrezuelos e una caxuela en Pedro de Leon en real e medio testigos Holmedo e Borjabaz LI (Leon)». ADM, Sección Medinaceli, leg. 102, doc. 6.

71. Sobre el coleccionismo de armas y armaduras de lujo, así como de otros objetos vinculados al mundo caballeresco, véase Jesús Félix Pascual Molina: «Lujo de acero. Armas y poder en el ámbito Habsbúrgico del siglo xvI», Ars E Renovatio, 7, 2019, pp. 363-378.

72. Esto se producirá con el IV Duque de Medinaceli, don Juan de la Cerda y Silva, Raúl Romero Medina: "Como la espada, así la vaina. La colección de armas blancas de don Juan de la Cerda y Silva, IV Duque de Medinaceli (1552-1575)», Potestas: Religión, poder y monarquía. Revista del Grupo Europeo de Investigación Histórica, 16, 2020, pp. 81-102.

73. AdM, Sección Medinaceli, leg. 102, doc. 6. 


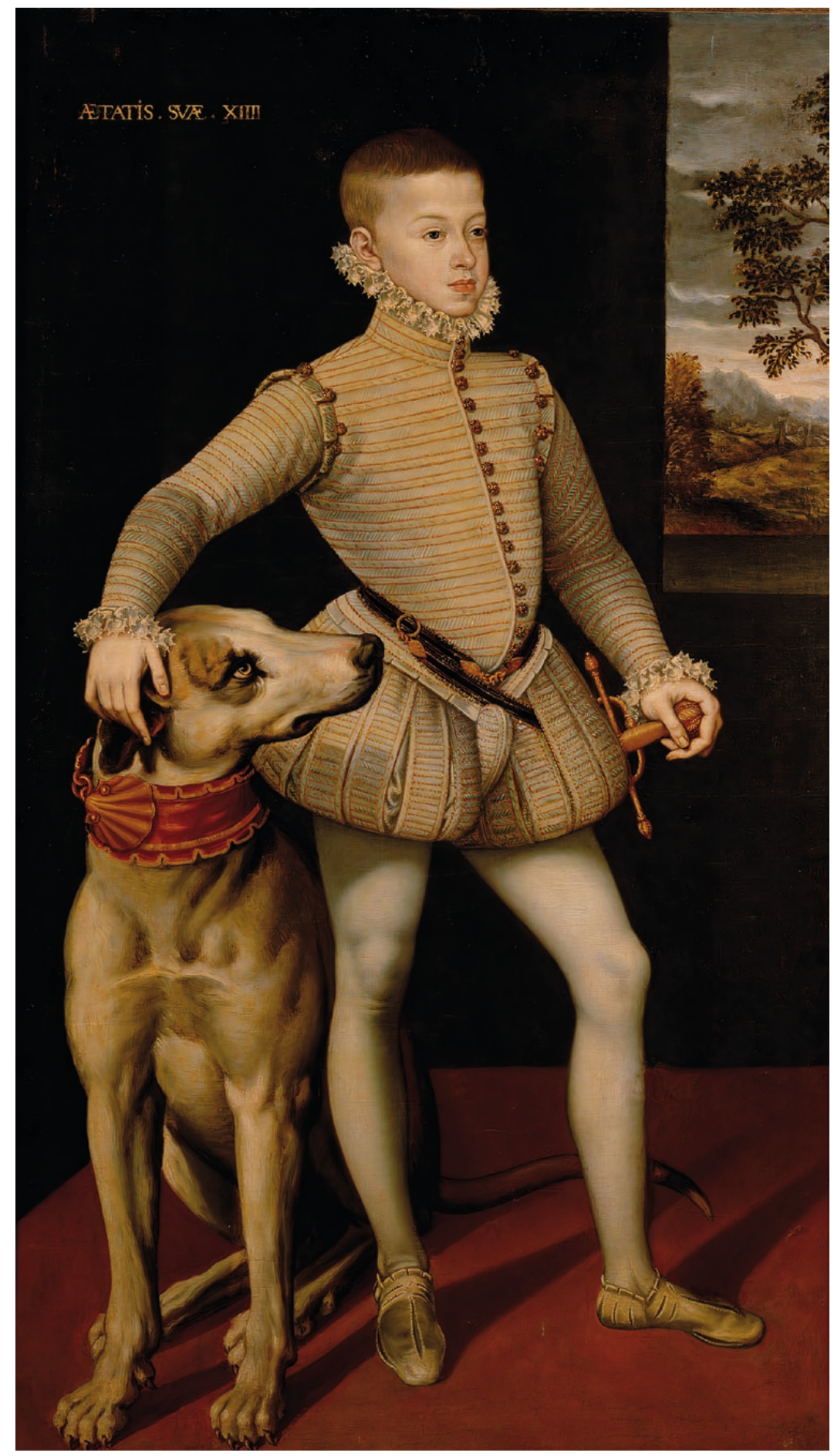

Figura 5. Retrato del archiduque Alberto VII, Alonso Sánchez Coello, c. 1573, 164 x 98 cm, óleo sobre lienzo, Kunsthistorisches Museum, Viena, Gemäldegalerie, 9699 
Entre los «ornamenta» a los que se refiere G. B. Pontano los tapices tuvieron un papel destacado. ${ }^{74}$ Es con el II Duque de Medinaceli cuando tenemos una información un poco más completa sobre los tapices de la Casa ${ }^{75}$ información que se extrae del cargo que se le hizo a Francisco de Barrionuevo sobre «la ropa y tapiceria de la casa». ${ }^{76}$

Así, en torno a 1520 disponemos de una relación de paños aunque parca en descripción, si bien excluyendo paños de buriel, es decir paños de color natural de la lana, goteras, paños de cama o doseles, este arroja un número de 36 piezas. En el inventario se citan paños grandes, paños de figuras pequeños, reposteros de armas o paños de verduras, estos últimos muy frecuentes tanto en los talleres de Arrás como en los de Tournai y eran adquiridos por los nobles por ser más baratos. A principios del siglo XVI, las llamadas tapicerías de verduras, boscajes o galerías y millefleurs, también servían de fondo a escenas o blasones y se tejían tanto en los talleres de Tournai como en los de Brujas o Bruselas, siendo más naturalistas estos últimos que salieron del taller de Pannemaker. ${ }^{77}$

La almoneda de 1549 no arroja apenas información sobre este asunto y solo se asienta en ella el remate de «quatro paños de raso carmesi colchados biejos rotos hechos pedaços que eran de una cama bordada de oro e seda». ${ }^{78}$ En realidad, todo apunta a que el II Duque no poseyó grandes tapicerías de ciclos y estas piezas formarían parte del ajuar doméstico necesario para el decoro de un noble y militar. Son piezas de uso común en cualquier inventario de bienes de la época, ligadas a modas y a horizontes ideológicos relacionados con la magnificencia y, por tanto, lejos del ejercicio de coleccionar. De hecho, no será hasta la segunda mitad del siglo XVI cuando nos encontremos grandes tapicerías en la Casa de Medinaceli. ${ }^{79}$

En definitiva, los objetos que poseyó el II Duque de Medinaceli, plata, joyas, tapices, armas, etc., reflejan muy bien ese mundo y sentido práctico atribuido a lo que hoy entendemos como obra de arte. En realidad, no deja de ser el reflejo de la manifestación cultural del Renacimiento a la que le gusta-

74. Miguel Ángel Zalama Rodríguez (dir.): Magnificencia y arte. Devenir de los tapices en la Historia, Editorial Trea, Madrid, 2018.

75. En realidad tenemos noticia desde el III Conde de Medinaceli y su mujer doña Juana Sarmiento. El I Duque de Medinaceli entregó como ajuar a su hija doña Leonor de la Cerda al casar con el marqués de Cenete algunas piezas destacadas, como una cama o la tapicería de la Historia de Nabucodonosor. Sobre este asunto, RAúl Romero MEdina, «La promoción artística...», en prensa.

76. Raúl Romero Medina: «Génesis y legado de una colección nobiliaria en el siglo xvi. Los tapices de la Casa Ducal de Medinaceli», Goya, Revista de Arte, 375, 2021, pp.112-125.

77. Roger. A. D’Hulst: Tapisseries Flamandes du XIV ${ }^{e}$ au XVIII ${ }^{e}$ siècle, Arcade, Bruxelles, 1972, p. 261.

78. ADM, Sección Medinaceli, leg. 102, doc. 6.

79. Raúl Romero Medina: «Génesis y legado...», 2021, pp.112-125. Raúl Romero Medina, «La promoción artística...», en prensa. 
ba contraponer y complementar objetos, y que tuvo como tópico la aparente diferencia entre dos mundos: el de las armas y el de las letras.

Esta relación de objetos heteróclitos, lejos de formar una colección, es el reflejo de unas piezas que formaban parte de los bienes libres del poseedor y que se empeñaban, pignoraban o vendían en almoneda para cumplir mandas y legados testamentarios. Así, todavía en 1594 el nieto del II Duque de Medinaceli, Juan Luis de la Cerda, V duque de dicho título, señalaba en su codicilo cómo sus joyas y piezas de oro podían servir a su hijo como resguardo y empeño de sus deudas. Sin duda, con el valor de estos objetos se podía «muy holgadamente pagar las deudas y sobrar cantidad». ${ }^{80}$ Fue la ventaja que tuvo el dispendio de la magnificencia.

\section{DISCUSIÓN Y PROSPECTIVA}

Los inventarios son el reflejo de la concreción del concepto de magnificencia cortesana en el universo de bienes del entorno doméstico nobiliario. Sin embargo, en estos documentos se rastrean otro tipo de narrativas de poder alternativas a la magnificencia. Aunque no es el objeto de estudio de este trabajo, cabe señalar que para la construcción de la imagen, de la memoria y de la toma de consciencia propia del linaje, los Medinaceli se sirvieron de la narrativa genealógica. Así, la autoimagen nobiliar y la articulación de sus discursos genealógicos, como instrumento ideológico al servicio de la construcción de su memoria, se reflejó por ejemplo en las galerías de retratos familiares y reales. En este último caso, la presencia de retratos reales debe ser entendida en términos de geopolítica estratégica y de adhesión a la causa de la monarquía de los Habsburgo, teniendo en cuenta que los miembros del linaje ejercieron cargos en el servicio y en la privanza regia.

Los duques de Medinaceli no necesitaron acudir a valores, arquetipos o representaciones de un pasado mítico, pues eran descendientes del rey Alfonso X, el Sabio, pero sí acudieron, en esa consciencia del valor humanístico de la historia, a las representaciones de los emperadores romanos o a la referencia al mito de Hércules, este último tejido en ricas tapicerías de Flandes. No es el momento, por otro lado, de detenerse para contextualizar este caso de estudio en el panorama europeo contemporáneo, aunque quizá nos ayudaría a entender mejor la fuerza de la relación con Italia o Flandes en comparación con otros territorios.

En cualquier caso estos objetos de la magnificencia destacaron por su valor de portabilidad y así las vajillas, los tapices, la plata o las joyas acompañaron

80. Raúl Romero Medina, «La promoción artística...», en prensa. 
al duque don Juan de la Cerda en sus ceremonias escenográficas en los espacios áulicos de Medinaceli y Cogolludo. Estas piezas reflejan el poder y, al fin y al cabo, como señala el profesor Nieto Soria, ${ }^{81}$ este modifica el espacio en el que se exhibe actuando a su vez de marco inevitable de cada acción política. El lujo asociado a la magnificencia no dejaba de ser una estrategia política, aunque solo fuese porque el gasto dispendioso era un marcador de clases en la sociedad del Antiguo Régimen, habida cuenta de que el pobre no podía ser magnífico.

\section{BIBLIOGRAFÍA}

Barrón García, Aurelio: La época dorada de la platería burgalesa. 1400-1600. Diputación Provincial de Burgos, Valladolid-Burgos, 1998.

Burke, Peter: «Renaissance jewels in their Social Setting», Princely Magnificence: Court Jewels of the Renaissance, 1500-1630, Carswell Legal Pubns, London,1980.

Cañas Gálvez, Francisco de Paula: «La cámara de Juan II: vida privada, ceremonia y lujo en la Corte de Castilla a mediados del siglo XV», en Gambra Gutiérrez, Andrés y Labrador Arroyo, Félix (coords.): Evolución y estructura de la Casa Real de Castilla, Polifemo, Madrid, 2010.

- y Nieto Soria, José Manuel: Casa y Corte. Ámbitos de poder en los reinos hispánicos durante la Baja Edad Media (1230-1516), La Ergástula, Madrid, 2019.

Carriazo Rubio, Juan Luis: «La casa y corte de los señores de Marchena a finales de la Edad Media», en Cañas Gálvez, Francisco de Paula y Nieto Soria, José Manuel (coords.): Casa y Corte. Ámbitos de poder en los reinos hispánicos durante la Baja Edad Media (1230-1516), La Ergástula, Madrid, 2019.

Checa Cremades, Fernando: Los inventarios de Carlos $V$ y la familia imperial, Fernando Villaverde Ediciones, Madrid, 2010.

- Renacimiento habsbúrgico. Felipe II y las imágenes artísticas, Universidad de Valladolid, Valladolid, 2018.

D’Hulst, Roger. A.: Tapisseries Flamandes du XIV a 1972.

Fagel, Raymond. P.: «Poner la Corte en orden, poner orden en la Corte. Los cambios en la Casa de Borgoña alrededor del primer viaje hispánico de Carlos V (1515-17)», en HorTAL Muñoz, José Eloy y Labrador Arroyo, Félix (ed.): La Casa de Borgoña. La Casa del Rey de España, Leuven University Press, Louvain, 2014.

Fernández de Bethencourt, Francisco: Historia genealógica y heráldica de la monarquía española. Casa Real y Grandes de España, Fabiola de Publicaciones, Sevilla, 2003.

Foronda y Aguilera, MANuel de: Estancias y viajes del Emperador Carlos V desde el día de su nacimiento hasta el de su muerte[...], s.l; s.n., 1914.

González García, JuAn Luis: «Prácticas de reciclaje y auto-consciencia familiar en el coleccionismo artístico de los Habsburgo", en Checa Cremades, Fernando (dir.): Museo Imperial. El coleccionismo artístico de los Austrias en el siglo XVI, Fernando Villaverde Ediciones, Madrid, 2013.

81. Francisco de Paula Cañas Gálvez y José Manuel Nieto Soria (coords.): «Casa y Corte...», p. 9.

ISSN: 1888-9867 | e-ISSN 2340-499X | http://dx.doi.org/10.6035/Potestas.2021.19.3 
GonzÁlez Ramos, Roberto: «Imágenes, libros y armas. Tipología y significado de los bienes de Diego Hurtado de Mendoza, conde Saldaña y marqués de Cenete (1520-1560)», Anuario del Departamento de Historia y Teoría del Arte, 21, 2009.

Ladero Quesada Miguel Ángel: La Casa Ducal de Medina Sidonia en Sevilla y su reino (1282-1521), Dykinson, Madrid, 2015.

Mancini, Matteo (ed.): Memoria. Historia y espacios del Arte en el tiempo de los Habsburgo a través de archivos e inventarios, Sílex, Madrid, 2020.

Martínez de Aguirre, Javier: «Imagen e identidad en la arquitectura medieval hispana: carisma, filiación, origen y dedicación», Codex Aqvilarensis, 31, 2015.

Pascual Molina, Jesús FÉlix: «Magnificencia y poder en los festejos caballerescos de la primera mitad del siglo xvi», en Inmaculada Rodríguez Moya y Víctor Mínguez (dirs.): Visiones de un Imperio en fiestas, Fundación Carlos de Amberes, Madrid, 2016.

- «Lujo de acero. Armas y poder en el ámbito Habsbúrgico del siglo XVI», Ars \& Renovatio, 7, 2019.

Pontano, Giovanni Battista: I libri delle virtù, F. Tateo (ed.), Roma: Bulzoni, 1999.

Romero Medina, Raúl: «El palacio tardogótico castellano como arma de proyección social del linaje. Del Infantado a Cogolludo», Boletín de la Asociación de Amigos del Museo de Guadalajara, 6, 2015.

— «Plateros tardogóticos de Valladolid al servicio de la Casa Ducal de Medinaceli. A propósito de ciertas joyas para doña María de Silva y Toledo», Espacio, Tiempo y Forma, Serie VII, 6, 2018.

- «Como la espada, así la vaina. La colección de armas blancas de don Juan de la Cerda y Silva, IV Duque de Medinaceli (1552-1575)», Potestas: Religión, poder y monarquía. Revista del Grupo Europeo de Investigación Histórica, 16, 2020.

- «Génesis y legado de una colección nobiliaria en el siglo XVI. Los tapices de la Casa Ducal de Medinaceli», Goya, Revista de Arte, 375, 2021.

- «Il taisent la mémoire à la postérité». La galerie des portraits des ducs de Medinaceli dans le contexte du collectionisme des Habsbourg, Revue de l'Art, 212, 2021-2.

- La promoción artística de la Casa Ducal de Medinaceli. Memoria visual y arquitectura en Andalucía y Castilla (siglos XIV-XVI), Ediciones Doce Calles, Madrid, 2021, en prensa.

- «El palacio de Cogolludo en contexto: una residencia para la Casa y corte del duque de Medinaceli a finales del siglo xv», Lexicon. Storie e Archittetura in Sicilia, 2021, en prensa.

SÁnchez González, Antonio: «Don Juan de la Cerda, un portuense al frente de la Casa de Medinaceli», Revista de Historia de El Puerto, 29, 2002.

Urquízar Herrera, Antonio: Coleccionismo y nobleza. Signos de distinción social en la Andalucía del Renacimiento, Marcial Pons, Madrid, 2007.

- «Teoría de la Magnificencia y teoría de las señales en el pensamiento nobiliario español del siglo XVI», Ars Longa, cuadernos de Arte, 23, 2014.

YARZA LuACES, JOAQUín: La nobleza ante el Rey. Los grandes linajes castellanos y el arte en el siglo XV, Fundación Iberdrola, Madrid, 2003.

Zalama Rodríguez, Miguel Ángel: «La corona y el collar de Isabel la Católica y la financiación del I viaje de Colón», en Valera Marcos, Jesús y León Guerrero, María Montserrat (coords.): Actas del Congreso Internacional V Centenario de la Muerte del Almirante, Universidad de Valladolid, Valladolid, 2006.

- «Dejo y mando graciosamente al dicho príncipe todas las tapicerías. Felipe II y su interés por los tapices», en ÍDEM (coord.): El legado de las obras de arte: tapices, pinturas, esculturas...sus viajes a través de la historia, Universidad de Valladolid, Valladolid, 2017.

- (dir.): Magnificencia y arte. Devenir de los tapices en la Historia, Editorial Trea, Madrid, 2018. 
APÉNDICE I.

SERVIDORES DE LA CASA Y CORTE DE JUAN DE LA CERDA, II DUQUE
DE MEDINACELI, 1534-1535. ${ }^{82}$

\begin{tabular}{cccc}
\hline ORDEN & PERSONA & CARGO & SALARIO \\
\hline 1 & Alonso de la Cerda & Hermano del duque & $100.000 \mathrm{mrs}$ \\
2 & Pedro de la Cerda & Hermano del duque & $100.000 \mathrm{mrs}$ \\
3 & Luis de la Cerda & Primo del duque & $100.000 \mathrm{mrs}$ \\
4 & Alonso de Mendoza & & $100.000 \mathrm{mrs}$ \\
5 & Luis de Mendoza & Maestresala & $55.000 \mathrm{mrs}$ \\
6 & Felipe de Gamarra & & \\
7 & Francisco de Andrada & Maestresala & $45.000 \mathrm{mrs}$ \\
8 & Juan de Andrada & Oficial & $30.000 \mathrm{mrs}$ \\
9 & Ciego de Andrada & Capitán de la guardia & $30.000 \mathrm{mrs}$ \\
10 & Pablo de Salazar & Oficial & $24.000 \mathrm{mrs}$ \\
11 & Hernando de Torres & Camarero & $24.000 \mathrm{mrs}$ \\
12 & Francisco de Medrano & Oficial & $25.000 \mathrm{mrs}$ \\
13 & Luis Manuel & Trinchante & $22.000 \mathrm{mrs}$ \\
14 & Arnao & Trinchante & $22.000 \mathrm{mrs}$ \\
15 & Sazedo & Caballerizo & $22.000 \mathrm{mrs}$ \\
16 & Guterriañez & Oficial & $24.000 \mathrm{mrs}$ \\
17 & Luis Carrillo & Oficial & $23.000 \mathrm{mrs}$ \\
18 & Tormes & Caballerizo de mulas & $20.000 \mathrm{mrs}$ \\
19 & Francisco de Aguilera & Oficial de la cámara & $20.000 \mathrm{mrs}$ \\
20 & Mexia & Oficial & $8.000 \mathrm{mrs}$
\end{tabular}

82. Elaboración propia a partir de la fuente conservada en ADM, Sección Medinaceli, leg. 68, doc. 7.

83. En su testamento (1544) se le cita como Francisco de Gamarra y es el mismo porque se dice que estuvo al menos veinticinco años a su servicio. Al ser un traslado de fecha posterior, es posible que sea una mala transcripción del escribano. En cualquier caso, podría tratarse del Francisco de Gamarra que aparece en 1534-1535 como paje de copa y que pudo luego promocionar a maestresala. Era frecuente que estos cargos se heredaran de padres a hijos, teniendo en cuenta que mucho de estos cortesanos mantenían una estricta fidelidad a la Casa del duque.

84. En su testamento (1544) se le nombra Martín de Salzedo, su caballerizo ya difunto, que le prestó cuarenta ducados en dineros. 


\begin{tabular}{|c|c|c|c|}
\hline ORDEN & PERSONA & CARGO & SALARIO \\
\hline 21 & Covarrubias & Capellán & $15.000 \mathrm{mrs}$ \\
\hline 22 & Hurtado & Capellán & $15.000 \mathrm{mrs}$ \\
\hline \multirow[t]{2}{*}{23} & Jerónimo López & Oficial de cámara & $10.500 \mathrm{mrs}$ \\
\hline & & OFICIALES & \\
\hline 24 & Juan Ruizmalo & Contador & $20.000 \mathrm{mrs}$ \\
\hline 25 & Hernando de la Mota & Secretario & $30.000 \mathrm{mrs}$ \\
\hline 26 & Alonso de Barrionuevo & Receptor & $30.000 \mathrm{mrs}$ \\
\hline 27 & Mondragón & Secretario & $30.000 \mathrm{mrs}$ \\
\hline 28 & Licenciado Vázquez & Físico & $100.000 \mathrm{mrs}$ \\
\hline 29 & Rodrigo de León & Oficial & $30.000 \mathrm{mrs}$ \\
\hline 30 & Juan de León & Oficial & $20.000 \mathrm{mrs}$ \\
\hline 31 & Lope de Morales & Veedor & $11.000 \mathrm{mrs}$ \\
\hline 32 & Licenciado López & Letrado de Granada & $6.000 \mathrm{mrs}$ \\
\hline 33 & Antón Pez & Procurador de Granada & $3.000 \mathrm{mrs}$ \\
\hline 34 & Diego Ortiz & Clérigo-religioso & $2.000 \mathrm{mrs}$ \\
\hline 35 & Juan de Salazar & Solicitador & $24.000 \mathrm{mrs}$ \\
\hline 36 & Bachiller Salazar & Solicitador & $30.000 \mathrm{mrs}$ \\
\hline 37 & Yllanes & Solicitador en la Corte & $35.000 \mathrm{mrs}$ \\
\hline \multirow[t]{2}{*}{38} & Înigo Laínez & Oficial & $6.000 \mathrm{mrs}$ \\
\hline & & OTROS OFICIALES & \\
\hline 39 & Ocalez & Despensero & $8.000 \mathrm{mrs}$ \\
\hline 40 & Pedro Daza & Boticario & $15.000 \mathrm{mrs}$ \\
\hline 41 & Juan & Cirujano & $17.000 \mathrm{mrs}$ \\
\hline 42 & Soto & Barbero & $5.000 \mathrm{mrs}$ \\
\hline 43 & Alonso Ortiz & Acemilero mayor & $8.000 \mathrm{mrs}$ \\
\hline 44 & Francisco & Cocinero & $15.000 \mathrm{mrs}$ \\
\hline 45 & Hernando de Camino & Veedor de obras & $4.000 \mathrm{mrs}$ \\
\hline 46 & Albornoz & Oficial & $5.000 \mathrm{mrs}$ \\
\hline 47 & Hernando de Palda & Sastre & $5.000 \mathrm{mrs}$ \\
\hline
\end{tabular}




\begin{tabular}{|c|c|c|c|}
\hline ORDEN & PERSONA & CARGO & SALARIO \\
\hline 48 & Fea & Calcetero & $2.000 \mathrm{mrs}$ \\
\hline 49 & Bretes & Guarda de la dehesa & $3.000 \mathrm{mrs}$ \\
\hline 50 & Encinas & Zapatero & $4.000 \mathrm{mrs}$ \\
\hline \multirow[t]{2}{*}{51} & Pedro de Valdemedras & Sillero & $4.000 \mathrm{mrs}$ \\
\hline & \multicolumn{3}{|c|}{ REPOSTEROS } \\
\hline 52 & Juan Cavallo 85 & Repostero de plata & $12.000 \mathrm{mrs}$ \\
\hline 53 & Diego de Vega & Macero & $15.000 \mathrm{mrs}$ \\
\hline 54 & Lorenzo de Trujillo & Repostero & $10.000 \mathrm{mrs}$ \\
\hline 55 & Juan de Trujillo & Repostero & $10.000 \mathrm{mrs}$ \\
\hline 56 & Julian de Olmedo & Repostero & $10.000 \mathrm{mrs}$ \\
\hline 57 & Juan de Peñalva & Repostero & $10.000 \mathrm{mrs}$ \\
\hline 58 & Alonso de Espinosa & Botiller & $10.000 \mathrm{mrs}$ \\
\hline 59 & Lopez & Repostero & $10.000 \mathrm{mrs}$ \\
\hline 60 & Inés & Cerera & $10.000 \mathrm{mrs}$ \\
\hline 61 & Jerónimo de Torralva & Repostero & $12.000 \mathrm{mrs}$ \\
\hline 62 & Rodrigo de Angulo & Repostero & $12.000 \mathrm{mrs}$ \\
\hline 63 & Juan de Villel & Repostero & $12.000 \mathrm{mrs}$ \\
\hline 64 & Pedro de Frías & Repostero & $12.000 \mathrm{mrs}$ \\
\hline 65 & Aguilera & Repostero & $12.000 \mathrm{mrs}$ \\
\hline 66 & Miguel de Torralva & Repostero & $12.000 \mathrm{mrs}$ \\
\hline 67 & Camino & Repostero & $12.000 \mathrm{mrs}$ \\
\hline 68 & Bretes & Repostero & $12.000 \mathrm{mrs}$ \\
\hline 69 & Jerónimo Rodríguez & Repostero & $12.000 \mathrm{mrs}$ \\
\hline \multirow[t]{2}{*}{70} & Bretes & Repostero & $12.000 \mathrm{mrs}$ \\
\hline & \multicolumn{3}{|c|}{ TROMPETAS } \\
\hline 71 & Paredes & Trompeta & $13.000 \mathrm{mrs}$ \\
\hline 72 & González de Hinojosa & Trompeta & $13.000 \mathrm{mrs}$ \\
\hline 73 & Gaspar de Benavente & Trompeta & $13.000 \mathrm{mrs}$ \\
\hline
\end{tabular}

85. En su testamento se le menciona como Juan Caballero. 


\begin{tabular}{|c|c|c|c|}
\hline ORDEN & PERSONA & CARGO & SALARIO \\
\hline 74 & Hontañón & Trompeta & $13.000 \mathrm{mrs}$ \\
\hline 75 & Juan López & Trompeta & $13.000 \mathrm{mrs}$ \\
\hline 76 & Gregorio de Soto & Trompeta & $13.000 \mathrm{mrs}$ \\
\hline 77 & Hernando de Aguilera & Trompeta & $13.000 \mathrm{mrs}$ \\
\hline 78 & Fernando Pez & Trompeta & $13.000 \mathrm{mrs}$ \\
\hline 79 & Cornejo & Atabalero & $3.000 \mathrm{mrs}$ \\
\hline 80 & Torderrava & Trompeta & $2.000 \mathrm{mrs}$ \\
\hline \multirow[t]{2}{*}{81} & Juan de Esteras & Trompeta & $2.500 \mathrm{mrs}$ \\
\hline & & CAZADORES & \\
\hline 82 & Juan Cazador & Cazador & $20.000 \mathrm{mrs}$ \\
\hline 83 & Alonso de Almansa & Cazador & $15.000 \mathrm{mrs}$ \\
\hline 84 & Juan de Almansa & Cazador & $12.000 \mathrm{mrs}$ \\
\hline 85 & Martín Doña & Cazador & $15.000 \mathrm{mrs}$ \\
\hline 86 & Juan Catalán & Cazador & $25.000 \mathrm{mrs}$ \\
\hline 87 & Pero de Segovia & Cazador & $7.000 \mathrm{mrs}$ \\
\hline 88 & Antonio de Tavira & Cazador & $10.000 \mathrm{mrs}$ \\
\hline 89 & Contreras & Cazador & $6.000 \mathrm{mrs}$ \\
\hline 90 & Diego de Guinea & Cazador & $3.000 \mathrm{mrs}$ \\
\hline 91 & Villanueva & Cazador & $14.000 \mathrm{mrs}$ \\
\hline 92 & Antonio & Mozo de caza & $3.000 \mathrm{mrs}$ \\
\hline 93 & Diego de Montoya & Cazador & $3.000 \mathrm{mrs}$ \\
\hline 94 & Rederos & Cazador & $3.000 \mathrm{mrs}$ \\
\hline \multirow[t]{2}{*}{95} & Bustillo & Cazador & $3.000 \mathrm{mrs}$ \\
\hline & & PAJES & \\
\hline 96 & Francisco de Gamarra & Paje de copa & $6.000 \mathrm{mrs}$ \\
\hline 97 & Hurtado & Paje & $3.000 \mathrm{mrs}$ \\
\hline 98 & Charles de Valera & Paje & $3.000 \mathrm{mrs}$ \\
\hline 99 & Felipe & Paje de cámara & $3.000 \mathrm{mrs}$ \\
\hline 100 & Felipe de Gamarra & Paje de cámara & $3.000 \mathrm{mrs}$ \\
\hline
\end{tabular}




\begin{tabular}{|c|c|c|c|}
\hline ORDEN & PERSONA & CARGO & SALARIO \\
\hline 101 & Torres & Paje & $3.000 \mathrm{mrs}$ \\
\hline 102 & Rodrigo de Ávila & Paje & $3.000 \mathrm{mrs}$ \\
\hline 103 & Heredia & Paje & $3.000 \mathrm{mrs}$ \\
\hline 104 & Sazedico & Paje & $3.000 \mathrm{mrs}$ \\
\hline 105 & Castillo & Paje & $3.000 \mathrm{mrs}$ \\
\hline 106 & Martín de Andrada & Paje & $3.000 \mathrm{mrs}$ \\
\hline 107 & Guzmán & Paje & $3.000 \mathrm{mrs}$ \\
\hline 108 & Salazarico & Paje & $3.000 \mathrm{mrs}$ \\
\hline 109 & Medranico & Paje & $3.000 \mathrm{mrs}$ \\
\hline 110 & Cuellar & Paje & $3.000 \mathrm{mrs}$ \\
\hline 111 & Guzmán de Burgos & Paje & $3.000 \mathrm{mrs}$ \\
\hline 112 & Donarriquez & Paje & $3.000 \mathrm{mrs}$ \\
\hline \multirow[t]{2}{*}{113} & Medranico de Soria & Paje & $3.000 \mathrm{mrs}$ \\
\hline & \multicolumn{3}{|c|}{ OTROS OFICIALES } \\
\hline 114 & Juan de Torralva & Gallinero & $5.000 \mathrm{mrs}$ \\
\hline 115 & Hernando de Madrid & Oficial & $12.000 \mathrm{mrs}$ \\
\hline 116 & Ayala & Oficial & $3.000 \mathrm{mrs}$ \\
\hline 117 & Peñalba & Mozo brasero & $3.000 \mathrm{mrs}$ \\
\hline 118 & Juan Montañés & Polvorista & $3.000 \mathrm{mrs}$ \\
\hline 119 & Sazedo & Caballerizo & $4.000 \mathrm{mrs}$ \\
\hline 120 & & Mozo de caballo & $2.500 \mathrm{mrs}$ \\
\hline 121 & & Mozo de caballo & $2.500 \mathrm{mrs}$ \\
\hline 122 & & Mozo de caballo & $2.500 \mathrm{mrs}$ \\
\hline 123 & & Mozo de espuelas & $1.200 \mathrm{mrs}$ \\
\hline 124 & & Mozo de espuelas & $1.200 \mathrm{mrs}$ \\
\hline 125 & & Mozo de espuelas & $1.200 \mathrm{mrs}$ \\
\hline 126 & & Mozo de espuelas & $1.200 \mathrm{mrs}$ \\
\hline 127 & & Mozo de sala & $1.500 \mathrm{mrs}$ \\
\hline 128 & & Mozo de cocina & $1.200 \mathrm{mrs}$ \\
\hline
\end{tabular}




\begin{tabular}{|c|c|c|c|}
\hline ORDEN & PERSONA & CARGO & SALARIO \\
\hline 129 & & Mozo de cocina & $1.200 \mathrm{mrs}$ \\
\hline 130 & & Mozo de plata & $2.000 \mathrm{mrs}$ \\
\hline 131 & & Mozo de plata & $2.000 \mathrm{mrs}$ \\
\hline 132 & Brihuega & Mozo de capilla & $3.000 \mathrm{mrs}$ \\
\hline 133 & Vela & Mozo de capilla & $3.000 \mathrm{mrs}$ \\
\hline 134 & Pero Casado & Guarda de la dehesa & $1.000 \mathrm{mrs}$ \\
\hline \multirow[t]{2}{*}{135} & Juan de Herraminez & Guarda de la dehesa & $1.000 \mathrm{mrs}$ \\
\hline & & $\begin{array}{c}\text { MOZOS } \\
\text { DE ESPUELAS }\end{array}$ & \\
\hline 136 & Alixadre & Mozo de espuelas & $3.000 \mathrm{mrs}$ \\
\hline 137 & San Martín & Mozo de espuelas & $3.000 \mathrm{mrs}$ \\
\hline 138 & Jiménez & Mozo de espuelas & $3.000 \mathrm{mrs}$ \\
\hline 139 & Juan de Tafalla & Mozo de espuelas & $3.000 \mathrm{mrs}$ \\
\hline 140 & Martín de Llarena & Mozo de espuelas & $3.000 \mathrm{mrs}$ \\
\hline 141 & Martin de Juberias & Mozo de espuelas & $3.000 \mathrm{mrs}$ \\
\hline \multirow[t]{2}{*}{142} & Mateo de Tavira & Mozo de espuelas & $3.000 \mathrm{mrs}$ \\
\hline & & Hombres de pie & \\
\hline 143 & Santurde & Hombre de pie & $2.000 \mathrm{mrs}$ \\
\hline 144 & Calderón & Hombre de pie & $2.000 \mathrm{mrs}$ \\
\hline 145 & Juan de Váscones & Hombre de pie & $2.000 \mathrm{mrs}$ \\
\hline 146 & Pero de Vaides & Hombre de pie & $2.000 \mathrm{mrs}$ \\
\hline 147 & Juan de Morón & Hombre de pie & $2.000 \mathrm{mrs}$ \\
\hline 148 & Pero López & Hombre de pie & $2.000 \mathrm{mrs}$ \\
\hline
\end{tabular}

